\title{
Effecting dietary change
}

\author{
Ashley J. Adamson* and John C. Mathers \\ Human Nutrition Research Centre, School of Clinical Medical Sciences, Faculty of Medical Sciences, \\ University of Newcastle, Newcastle upon Tyne NE1 4LP, UK
}

\begin{abstract}
A world epidemic of diet-related chronic disease is currently being faced. In the UK incidence of obesity alone has tripled in the last 20 years and this trend is predicted to continue. Consensus exists for the urgent need for a change in diet and other lifestyle factors and for the direction and targets for this change. The evidence for how this change can be achieved is less certain. It has been established that disease processes begin in childhood. Recent evidence indicates that dietary habits too are established in childhood but that these habits are amenable to change. While establishing a healthy lifestyle in childhood is paramount, interventions have the potential to promote positive change throughout the life course. Success in reversing current trends in diet-related disease will depend on commitment from legislators, health professionals, industry and individuals, and this collaboration must seek to address not only the food choices of the individual but also the environment that influences such choices. Recent public health policy development in England, if fully supported and implemented, is a positive move towards this goal. Evidence for effective strategies to promote dietary change at the individual level is emerging and three reviews of this evidence are discussed. In addition, three recent dietary intervention studies, in three different settings and with different methods and aims, are presented to illustrate methods of effecting dietary change. Further work is required on what factors influence the eating behaviour and physical activity of individuals. There is a need for further theory-based research on which to develop more effective strategies to enable individuals to adopt healthier lifestyles.
\end{abstract}

Dietary change: Effective interventions

In the UK, as in the rest of the Western world, an epidemic of diet-related disease is being faced. Unprecedented increases in the prevalence of obesity and of obesityrelated diseases, including diabetes, CVD, hypertension and some forms of cancer, have led to urgent calls for action to prevent obesity (Department of Health, Chief Medical Officer, 2003). The National Audit Office (2001) has reported that obesity is responsible for $>9000$ premature deaths each year in England alone and reduces life expectancy by an average of 9 years. The World Health Organization (2002) estimates that approximately $58 \%$ of type 2 diabetes, $21 \%$ of CVD and $42 \%$ of some cancers are attributable to excess body fat. Prevalence of obesity has tripled in the past two decades; $21 \%$ of men and $24 \%$ of women are now obese while approximately $60 \%$ of adults are overweight or obese (Department of Health, Chief Medical Officer, 2003). Obesity impacts on both the short- and long-term health of children; therefore, the growth in the proportion of children who are overweight or obese is a major concern. Approximately $17 \%$ of children aged 2-15 years are obese (Department of Health, Chief Medical Officer, 2003). The emergence of type 2 diabetes in obese children gives cause for particular concern (Ehtisham et al. 2004) and is a potent indicator of a major long-term health problem. Socio-economic trends are evident in the incidence of diet-related disease; whilst $16 \%$ of higher-social-class men and women are obese, this percentage rises to 23 for men and 29 for women from 'unskilled manual' families (National Audit Office, 2001). The cost of the health burden of obesity is estimated to be at least $£ 2.5 \times 10^{9}$ /year, including the cost to the National Health Service and industry. This cost is predicted to increase. This problem is not unique to the UK, since the burden of chronic disease is increasing

\footnotetext{
Abbreviation: FE, food energy.

*Corresponding author: Dr Ashley Adamson, fax +44 191222 5276, email A.J.Adamson@newcastle.ac.uk
} 
worldwide. Chronic disease accounts for approximately $60 \%$ of the $56.5 \times 10^{6}$ deaths each year worldwide and for $46 \%$ of the global burden of disease. These levels are expected to increase to $75 \%$ and $57 \%$ respectively by 2020 (World Health Organization/Food and Agriculture Organization, 2003).

The recent unprecedented media and public interest in nutrition echoes the concerns of those agencies that set public health policies. There is worldwide consensus for the urgent need for dietary change to halt the epidemic of dietrelated disease. The recent World Health Organization/ Food and Agriculture Organization (2003) expert consultation on diet, nutrition and prevention of chronic disease has recognised that the growing epidemic of chronic disease in both developed and developing countries is related to dietary and other lifestyle factors. The rapid changes in diet and lifestyle that have paralleled economic development and market globalisation have accelerated in the past decade, with a considerable impact on the health of populations worldwide. Whilst food availability has expanded and diversified and standards of living have improved, there have been negative consequences of inappropriate dietary patterns and decreased physical activity, resulting in an increase in diet-related chronic disease, particularly among poorer groups within the population.

The intention of primary prevention interventions is to move the profile of the whole population in a healthier direction. Small changes can have an enormous impact in terms of population-attributable risk. Small reductions, e.g. in blood pressure or blood cholesterol concentrations, have the potential to dramatically reduce the health burden of diet-related disease. There is now substantial evidence that improved lifestyles can have a major effect on health. For example, improved diet and/or increased physical activity have been shown to reduce the risk of progression to diabetes in those individuals with impaired glucose tolerance by $58 \%$ over 4 years (Tuomilehto et al. 2001; Diabetes Prevention Program Research Group, 2002). Other researchers have argued that $\leq 80 \%$ of cases of CHD and $\leq 90 \%$ of type 2 diabetes could potentially be avoided through lifestyle change, and about one-third of cancers could be avoided by eating more healthily, maintaining a normal weight and exercising throughout life (Stampfer et al. 2000; Hu et al. 2001; Key et al. 2002). The World Health Organization/Food and Agriculture Organization (2003) report has called for a shift in the conceptual framework for developing strategies for action to place nutrition, together with tobacco use and alcohol consumption, at the forefront of public health policies.

There is also worldwide consensus on the changes in diet that are required and on the need for increased physical activity. World Health Organization/Food and Agriculture Organization (2003) have reviewed the evidence for diet in the prevention of obesity, diabetes, CVD, cancer, dental disease and osteoporosis. The evidence for each dietrelated disease has been used to develop recommendations for population goals that are consistent, i.e. the evidence for dietary patterns that will help prevent obesity is consistent with recommendations for reducing the risk of other diet-related diseases, including cancer, diabetes and CVD. Unlike the potential impact of a pharmacological approach to disease prevention, the promotion and adoption of dietary change in line with these goals has the potential to reduce the incidence of all diet-related diseases. Within the UK these goals translate to: a reduction in intakes of total fat and of saturated fatty acids and trans-fatty acids, accompanied by an increase in MUFA; an increase in total carbohydrate with a reduction in free (or non-milk extrinsic) sugars; a reduction in $\mathrm{Na}$ intake; an increase in fruits and vegetables to $400 \mathrm{~g} / \mathrm{d}$; an increase in wholegrain foods, fruits and vegetables to increase intake of NSP to $>20 \mathrm{~g} / \mathrm{d}$. While the precise values for these goals may differ slightly, they are consistent with UK dietary reference values (Department of Health, 1991) and also with the aims of the recent consultation document on priorities for a food and health action plan (Choosing Health? Choosing a Better Diet; Department of Health, 2004a).

Whilst consensus exists not only for the urgent need for dietary change but also in relation to the direction and extent of that change, it is much less clear how such changes can be achieved. What is the evidence for effective dietary change? At what stage of the life course should this change be targetted? Should children or adults be the focus for change? The present paper explores this issue and presents some of the evidence of the characteristics of effective interventions. Also presented are the approaches used and the findings from three recent studies that have aimed to change diet in adults, in children and in families in three different settings. To address the question of when in the life course interventions should focus, the results of a recent study that has measured the extent of tracking of dietary intake from childhood to adulthood is discussed.

\section{Tracking of diet and adiposity from adolescence to adulthood}

The major biological and behavioural risk factors emerge and act in early life, and continue to have a negative impact throughout the life course. Dietary habits in childhood will impact on growth, development and disease risk throughout life (Wright et al. 2001; World Health Organization/Food and Agriculture Organization, 2003). A recent study has aimed to establish the extent to which not only disease risk (obesity) but also eating habits are established early in life.

\section{Tracking of BMI}

While there is good evidence that obesity in childhood predicts obesity in adulthood, there is little evidence for the maintenance or 'tracking' of dietary intake. Tracking is used here to describe the maintenance of relative position within a population (Wardle, 1995). In 1980, 405 children completed two $3 \mathrm{~d}$ estimated food diaries followed by interviews. Mean daily intake was calculated. The heights and weights of the children were also recorded (Hackett et al. 1984). In 2000 these 'children', then aged 33 years, were traced and recruited to participate in a further study of diet and body composition using the same methods employed in the previous study (ASH30 Study). A total of $298(73 \%)$ subjects were traced and $202(49 \%)$ completed all aspects of the study. There was a highly significant 


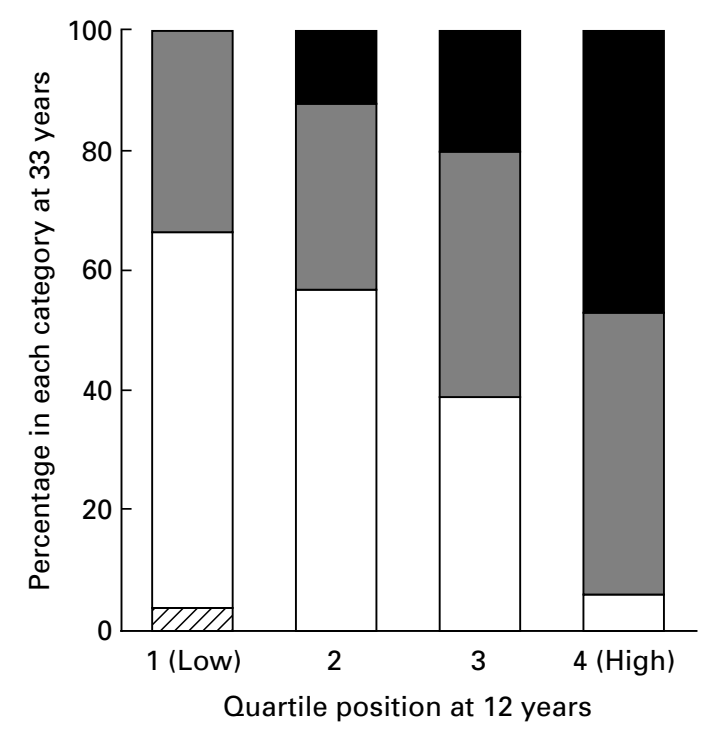

Fig. 1. The ASH30 Study: incidence of overweight and obesity at age 33 years by quartile of BMl at age 12 years. ( $), \geq 30 \mathrm{~kg} / \mathrm{m}^{2}$; $(\square), 25-30 \mathrm{~kg} / \mathrm{m}^{2} ;(\square), 18.5-25 \mathrm{~kg} / \mathrm{m}^{2} ;(\square),<18.5 \mathrm{~kg} / \mathrm{m}^{2}$. For details of study, see p. 538. (From Craigie et al. 2003.)

correlation $(P<0 \cdot 001, r+0 \cdot 56)$ between BMI at age 12 years and that at age 33 years. When considered by quartile of BMI at age 12 years, of those children in the lowest quartile of BMI at age 12 years, $65 \%$ were of healthy body weight (BMI $20-25 \mathrm{~kg} / \mathrm{m}^{2}$ ), $34 \%$ were overweight (BMI $25-29 \cdot 9 \mathrm{~kg} / \mathrm{m}^{2}$ ) and none was obese (BMI > $29.9 \mathrm{~kg} / \mathrm{m}^{2}$ ) as adults compared with those children who were in the highest quartile of BMI at age 12 years, of whom only $6 \%$ were of healthy body weight as adults while $47 \%$ were overweight and a further $47 \%$ were obese (Fig. 1; Craigie et al. 2003). These results demonstrate the tracking of adiposity and suggest that prevention of obesity should target children; but what about tracking of dietary intake?

\section{Tracking of diet}

Dietary intakes at ages 12 and 33 years were analysed in terms of the proportion of total food weight derived from each of the five sectors of the 'Balance of Good Health' plate model (Health Education Authority, Department of Health, and Ministry of Agriculture Fisheries and Food, 1994) and as nutrients. Food and nutrient intake were considered in terms of the change in intake between 1980 and 2000 , but also in relation to the extent to which intakes tracked over the 20-year period. In terms of change in food intake, fruit and vegetable intake increased markedly between adolescence and adulthood, from $15 \%$ total food weight to $25 \%$ total food weight. Similarly, marked changes were observed for foods containing fat and/or sugar, which fell from $21 \%$ food weight to $11 \%$ food weight. These changes in food groups were reflected in the observed changes in nutrient consumption. Intake of vitamin $\mathrm{C}$ increased by $115 \%(P<0.01)$, total sugar decreased by $17 \%$ $(P<0 \cdot 05)$ and fat decreased by $8 \%(P<0 \cdot 05)$. On this basis, it can be concluded that the diets of these adults aged 33 years in 2000 were markedly better, being closer to dietary targets (Department of Health, 1991) than the diets of the same subjects when aged 12 years in 1980 . In relation to tracking of food intake, three of the five 'Balance of Good Health' sectors (Health Education Authority, Department of Health, and Ministry of Agriculture Fisheries and Food, 1994) were found to have tracked significantly, i.e. fruit and vegetables $(r 0 \cdot 25, P<$ $0 \cdot 01)$, bread, other cereals and potatoes $(r 0 \cdot 24, P<0 \cdot 01)$ and meat, fish and alternatives $(r 0 \cdot 17, P<0 \cdot 05$; Lake et al. 2004). Significant tracking of food intakes was reflected to some extent in significant tracking of vitamin $\mathrm{C}(\mathrm{mg} / \mathrm{d}$; $r 0 \cdot 16, P<0 \cdot 01)$, total sugar $(\mathrm{g} / \mathrm{d} ; r 0 \cdot 25, P<0 \cdot 01)$ and fat $(\mathrm{g} / \mathrm{d} ; r$ 0·16, $P<0 \cdot 05$; Craigie et al. 2002).

The ASH30 Study provides some evidence to support the view that children should be one target for the promotion of a healthy diet and active lifestyles, since the foundations of many cases of adult obesity and lifelong dietary intake patterns are laid in childhood. Public health nutrition policy and the implementation of policy to promote healthy lifestyles in children are urgently required. The results from the ASH30 Study also demonstrate that food habits established in childhood are amenable to change, thus supporting the promotion of healthy lifestyles in adults. A life-course perspective on chronic disease prevention and control is critical, starting with maternal and child health and nutrition and carrying through to school and the workplace (World Health Organization/Food and Agriculture Organization, 2003).

\section{Evidence of effectiveness of dietary change}

The most persuasive evidence is provided by randomised controlled intervention studies, but such studies are expensive and difficult to design, conduct and evaluate. A number of recent reviews have examined the evidence for the effectiveness of interventions to promote dietary change and have drawn conclusions about the key characteristics of behavioural-change interventions that have been successful in promoting positive change. The findings of three such reviews (Roe et al. 1997; Ammerman et al. 2002; Pignone et al. 2003) will be discussed. These reviews include interventions based in institutions, e.g. schools and workplaces, in community groups, primary care, families or individuals and include interventions that focus on adults and children and on both healthy populations and at-risk individuals. The findings from these reviews are summarised in Table 1.

Roe et al. (1997) have reviewed health promotion interventions designed to promote healthy eating in the general population, where healthy eating is defined as a diet reduced in fat and increased in starchy foods and fruit and vegetables. A total of seventy-six studies are included in the review, but added weight is given to twenty-nine studies that were well designed and well conducted and that were judged to give more reliable evidence of effectiveness. The majority of good-quality studies have shown a beneficial effect of intervention, the most frequently measured outcome being dietary fat. Long-term interventions in the general population have achieved fat reductions 
Table 1. Summary of reviews of characteristics of effective interventions for effecting dietary change

\begin{tabular}{|c|c|c|c|}
\hline $\begin{array}{l}\text { Characteristics of effective } \\
\text { interventions }\end{array}$ & Roe et al. (1997) & Ammerman et al. (2002) & Pignone et al. (2003) \\
\hline \multicolumn{4}{|l|}{ Theoretical underpinning } \\
\hline Theoretical basis & & $\checkmark$ & \\
\hline $\begin{array}{l}\text { Behaviour change strategies or goal setting } \\
\text { Intensity and support }\end{array}$ & $\checkmark$ & $\checkmark$ & $\checkmark$ \\
\hline Higher intensity of intervention & & & $\checkmark$ \\
\hline Multiple contacts over time & $\checkmark$ & & \\
\hline Personal contact & $\checkmark$ & & \\
\hline Provision of feedback & $\checkmark$ & & \\
\hline Active involvement & $\checkmark$ & & \\
\hline Single rather than multiple focus (diet) & $\checkmark$ & & \\
\hline Social support for change & $\checkmark$ & $\checkmark$ & $\checkmark$ \\
\hline Family involvement & $\checkmark$ & $\checkmark$ & $\checkmark$ \\
\hline Utilise small group settings & $\checkmark$ & $\checkmark$ & $\checkmark$ \\
\hline \multicolumn{4}{|l|}{ Appropriate or personalised advice } \\
\hline Cultural specificity or advice appropriate to target group & & $\checkmark$ & $\checkmark$ \\
\hline Uses dietary assessment & & & $\checkmark$ \\
\hline Interactive tailored materials & & & $\checkmark$ \\
\hline Some extent of personalisation & $\checkmark$ & & \\
\hline Includes food-related activities & & $\checkmark$ & $\checkmark$ \\
\hline \multicolumn{4}{|l|}{ Change in food provision } \\
\hline Change in access or availability & $\checkmark$ & & \\
\hline Passive change in composition & $\checkmark$ & & \\
\hline
\end{tabular}

equivalent to $1-4 \%$ energy intake, while intensive interventions in highly-motivated subjects have achieved reductions of $10-16 \%$ energy intake. Intakes of other aspects of the diet have been less frequently reported and no study has shown a positive effect on consumption of fruit and vegetables, starchy foods or dietary fibre. The authors have identified characteristics of effective interventions and also those of less-effective interventions. Interventions in schools, workplaces, primary care and community settings that have had a sustained effect have tended to have: focused on diet only or on diet and exercise; incorporated behavioural theories and goals rather than provision of information alone; had personal contact with individuals or small groups with active involvement and behaviour change strategies; included some extent of personalisation of the intervention to individual characteristics; included provision of feedback, multiple contacts over time and encouraged support for change by involving family or wider community networks. Change in food composition passively or change to access of food choices have also been found to be effective.

Ammerman et al. (2002) have reviewed the evidence for the efficacy of behavioural interventions designed to modify dietary fat and fruit and vegetable intake from ninety-two independent studies, including randomised controlled trials and other study designs. Of the twenty-two studies that promoted fruit and vegetable intake, seventeen have reported significant increases in consumption that averaged 0.6 servings/d. Decreases in intakes of total fat and of saturated fatty acids for the twenty-five studies included are in the order of $7.5 \%$ reduction in the percentage energy from fat. A summary of this analysis is presented in Table 1. Features of effective interventions are those: (1) with a theoretical basis; (2) that have included a family component; (3) that have had some element of social support; (4) that have involved small groups; (5) that have included goal setting; (6) that have included some food related activity; (7) that have had cultural specificity. The characteristics that have been found to be most consistently associated with efficacy are goal setting and small groups (Ammerman et al. 2002).

Pignone et al. (2003) have reviewed twenty-one studies for evidence for the efficacy of counselling to promote a healthy diet in adult patients in the primary care setting. Here counselling is defined as 'a cooperative mode of interaction between patient and primary care professionals to assist patients in adopting behaviour associated with improved health outcomes'. Change in total fat, saturated fat, fruit and vegetable and fibre intakes have been reported and quantified by effect size into small, medium or large change. For example, for total fat intake, a difference of $>10 \%$ units is 'large', $5 \cdot 1-9.0 \%$ units is 'medium' and $\leq 5.0 \%$ units is 'small'. For fruit and vegetable intake a difference of one or more servings per $\mathrm{d}$ is considered 'large', 0.4-0.9 servings 'medium' and $<0.3$ servings 'small'. The review has also considered the intensity of the interventions, the risk status of patients, the study setting and the use of 'well-proven counselling elements'. The latter elements include: using dietary assessment; enlisting family involvement; providing social support; using group counselling; emphasising food interaction; encouraging goal setting; using advice appropriate to the patient group being studied (Ammerman et al. 2001). Perhaps not surprisingly, the review has found that higher-intensity interventions produce larger effect sizes than low-intensity interventions. When considering setting, primary care-based interventions produce small or medium effects. Studies that used interactive communication methods in primary care have a larger effect than standard counselling but smaller effects than those found in research clinic-based studies. 
Ammerman et al. (2001) have reported that many interventions are not described in sufficient detail to explore specific components of the interventions. However, where these elements have been reported, studies using a greater number of the components have a larger effect size. The review concludes that moderate- or high-intensity counselling interventions using interactive health communication tools, e.g. self-help materials, tailored mailings or telephone counselling, can reduce consumption of saturated fat and increase consumption of fruit and vegetables. Lowintensity interventions in unselected primary care adult patients produce small to medium changes in self-reported intakes. Medium- to high-intensity interventions generally produce greater changes, but are often used with at-risk patients or delivered in research clinics by highly-trained professionals to motivated patients so that their relevance to primary care settings is less apparent. Interventions using self-help materials and interactive communications along with brief advice produce medium changes and are feasible in primary care practices. Interventions that employ greater numbers of well-proven elements of counselling are more likely to produce a large or medium effect than those that use few or no counselling components.

Summarising the findings for all three reviews (Table 1), a number of common elements of effective interventions emerge: a theoretical basis with use of behaviour-change strategies; some facility for support for change, whether from family, small groups, feedback or multiple contacts; use of appropriate and personalised or tailored advice that may have basic dietary assessment or some active involvement. Additionally, food-related activities offer potential for intervention, as does change in food provision or access. Characteristics for target populations also affect outcome, with effect sizes of interventions being greater in populations known to be 'at risk'. The methods used to assess dietary intake in the studies cited in the reviews vary from self-completed checklists to detailed recording of intake. Evaluation of dietary interventions requires a robust tool by which to measure the primary outcome, i.e. change in dietary intake. Limitations in methods of dietary assessment continue to adversely influence the findings of intervention studies. The authors of all the reviews have commented on the need for further work to confirm the findings. World Health Organization/Food and Agriculture Organization (2003) have called for further research on what influences eating behaviour and physical activity, and have stated that there is a need, on a continuing basis, to develop strategies to change behaviour towards adopting healthy diets and lifestyles.

\section{Evidence into practice}

Three recently-completed intervention studies in different settings and with different population groups, but each with the aim of effecting dietary change, will be described. The focus of the first study, the BiO Project, was on the treatment of diet-related disease, in this case the treatment of obesity in primary care. The other two studies were tests of the efficacy of different approaches to achieving dietary change in healthy populations; the first study was in young children in a primary school setting and the second study was in families in a community setting. In each case the studies described are mapped on to the evidence for effecting dietary change (Roe et al. 1997; Ammerman et al. 2002; Pignone et al. 2003; Table 2).

Table 2. Elements of effective interventions utilised in three recent studies

\begin{tabular}{|c|c|c|}
\hline $\begin{array}{l}\text { BiO Project }{ }^{\star} \\
\text { (model of intervention } \\
\text { promoted low implemention) }\end{array}$ & Bash Street Kids Project† & $\begin{array}{l}\text { Family Food and Health Project } \\
\text { (interventions } \mathrm{A}, \mathrm{B} \text { and } \mathrm{C} \text { ) }\end{array}$ \\
\hline $\begin{array}{l}\text { Theoretical underpinning } \\
\text { Goal setting }\end{array}$ & $\begin{array}{l}\text { Theoretical underpinning } \\
\text { Theoretical basis }\end{array}$ & $\begin{array}{l}\text { Theoretical underpinning } \\
\text { Goal setting }(C)\end{array}$ \\
\hline Intensity of support & Intensity of support & Intensity of support \\
\hline Multiple contacts over time & Multiple contacts over time & Multiple contacts over time (B and $C$ ) \\
\hline Personal contact & Active involvement & Personal contact (B and $\mathrm{C}$ ) \\
\hline \multirow[t]{2}{*}{ Single focus } & Single focus & Feedback (C) \\
\hline & Social support & Active involvement (A, B and $C)$ \\
\hline Appropriate and personalised advice & Family involvement & Single focus (A, $B$ and $C)$ \\
\hline Interactive tailored materials & Small-group settings & Social support (B and $C)$ \\
\hline \multirow[t]{8}{*}{ Some extent of personalisation } & Appropriate or personalised advice & Family involvement (A, B and $C)$ \\
\hline & Appropriate to target group & Small-group settings (B and $C)$ \\
\hline & Interactive tailored materials & Appropriate or personalised advice \\
\hline & Food-related activities & Dietary assessment (C) \\
\hline & Change in food provision & Personalisation (C) \\
\hline & Change in access and availability & Appropriate to target group (C) \\
\hline & & Interactive tailored materials (A, B and C) \\
\hline & & Food-related activities (B and C) \\
\hline
\end{tabular}


Table 3. The BiO Project: difference in weight and BMI between patients from intervention and control practices $(\text { Moore et al. } 2003 a, b)^{\star}$

\begin{tabular}{|c|c|c|c|c|c|}
\hline & \multirow[b]{2}{*}{ Intervention } & \multirow[b]{2}{*}{ Control } & \multicolumn{2}{|c|}{$\begin{array}{c}\text { Difference } \\
\text { (intervention - control) }\end{array}$} & \multirow{2}{*}{$\begin{array}{c}\text { Statistical significance } \\
\text { of difference between } \\
\text { practices: } P=\end{array}$} \\
\hline & & & Mean & $95 \% \mathrm{Cl}$ & \\
\hline \multicolumn{6}{|l|}{ Weight $(\mathrm{kg})$} \\
\hline 3 months after training ( $n$ 664) & $100 \cdot 4$ & $99 \cdot 8$ & $+0 \cdot 6$ & $-2 \cdot 1,3 \cdot 2$ & $0 \cdot 70$ \\
\hline 12 months after training $(n 565)$ & $100 \cdot 3$ & $99 \cdot 3$ & $+1 \cdot 0$ & $-1.9,3.9$ & 0.50 \\
\hline 18 months after training ( $n 531)$ & $100 \cdot 8$ & $99 \cdot 5$ & $+1 \cdot 3$ & $-1 \cdot 8,4 \cdot 4$ & $0 \cdot 40$ \\
\hline \multicolumn{6}{|l|}{$\mathrm{BMI}\left(\mathrm{kg} / \mathrm{m}^{2}\right)$} \\
\hline 3 months after training $(n 663 \dagger)$ & $36 \cdot 8$ & $36 \cdot 9$ & -0.2 & $-1 \cdot 2,0 \cdot 8$ & $0 \cdot 70$ \\
\hline 12 months after training $(n 564 \dagger)$ & $36 \cdot 9$ & $36 \cdot 8$ & 0 & $-1 \cdot 0,1 \cdot 0$ & 0.96 \\
\hline 18 months after training $(n 529 t)$ & $37 \cdot 1$ & $36 \cdot 9$ & $0 \cdot 1$ & $-1 \cdot 0,1 \cdot 1$ & 0.90 \\
\hline
\end{tabular}

${ }^{*}$ For details of the project, see p. 542.

tHeight missing in one patient.

\section{A brief intervention for the management of obesity in UK primary care: The BiO Project}

In the UK primary care is the frontline for the treatment of obesity. The Department of Health (2002) has stated that primary care should 'use every opportunity to promote healthy lifestyles' and should provide advice on diet, weight reduction and exercise. A survey of general practitioners and practice nurses by the National Audit Office (2001) has identified several factors considered to be of assistance in the treatment of patients, including: more information on effective interventions; availability of better materials for advising patients; better training for staff. Little is known about how effective such training is in helping primary care teams to manage obesity more effectively. A systematic review of interventions to improve health professionals' management of obesity has found little rigorous research from which to draw conclusions (Harvey et al. 1999).

The BiO Project was a cluster randomised trial in which a training programme (the intervention) promoting the evidence-based treatment of obesity was delivered to general practice teams (unit of randomisation). Although many trials have measured the effectiveness of training, few have measured effectiveness at the level of health outcomes in patients. The primary outcome measure was difference in patients' weight. Secondary outcomes included difference in practitioners' knowledge and behaviour in weight-management consultations. Process evaluation included an audit of all patient records. A full report of this study has been published by Moore et al. (2003b).

The educational strategy was based on a previous nutrition training programme (Moore et al. 2003a). The programme promoted a model approach to obesity treatment that incorporated best evidence and was perceived to be brief enough that primary care staff could deliver it to their patients. Supporting written resources facilitated the dietary prescription to patients. At the end of the three training sessions practices devised individualised weightmanagement protocols based on the model and were encouraged to implement the weight-management strategies with patients recruited to the study. Table 2 shows which of the elements of effective interventions (shown in Table 1) are included in the model for the treatment of obesity promoted in this study. Control practices were asked to provide usual care to their patients.

A total of forty-four practices from four areas of northern England took part in the study. Details of the study design have been published elsewhere (Moore et al. 2001). In total 843 patients attended for collection of baseline data and were subsequently randomised. Table 3 shows the difference in patients' weight 12 months after the training; there was no significant difference in the weight of patients between the intervention and control groups.

There was an improvement in the practitioners' knowledge of the principles of obesity management, and trained practitioners were found to be more likely to implement the weight-management strategies promoted in the training. Patients from trained practices were seen more often and were more likely to have current weight, target weights and dietary targets documented in their records, but in absolute terms the level of implementation was low. In the year after delivery of the training, target weights were recorded for only $14 \%$ of the participating patients in trained practices, compared with only $3 \%$ of the participating patients in control practices.

The BiO Project promoted an evidence-based model of care and used evidence of effective education in the development of the training programme. While the training was well received it resulted in only limited implementation of an approach to obesity management and did not achieve improved patient weight loss. The low level of implementation of the obesity management model means that conclusions cannot be drawn about its effectiveness; however, it suggests that provision of training and resources is not sufficient to affect patients' weight. It is possible that such training, supported by targets for obesity management and financial resources, may have increased implementation levels. Other strategies to manage obesity in primary care urgently need to be considered and evaluated.

\section{A school-based nutrition education programme aimed at increasing fruit and vegetable intake in primary school-aged children: The Bash Street Kids Project}

High intakes of fruit and vegetables are associated with lower rates of diet-related disease (Key et al. 2002; World 
Table 4. The Bash Street Kids project: mean daily weight of fruit and vegetables ( $3 \mathrm{~d}$ food diaries) in intervention ( $n$ 64) and control groups ( $n$ 65; Anderson et al. 2001)*

(Values are means with their standard errors)

\begin{tabular}{|c|c|c|c|c|c|}
\hline & \multicolumn{2}{|c|}{ Baseline } & \multicolumn{2}{|c|}{9 months post implementation } & \multirow{2}{*}{$\begin{array}{l}\text { Intervention } \\
\text { effect: } P=\end{array}$} \\
\hline & Mean & SE & Mean & $\mathrm{SE}$ & \\
\hline \multicolumn{6}{|l|}{ Fruit $(\mathrm{g})$} \\
\hline Intervention & 133 & 11.9 & 183 & $17 \cdot 0$ & \multirow{2}{*}{0.042} \\
\hline Control & 100 & $11 \cdot 7$ & 107 & $14 \cdot 2$ & \\
\hline \multicolumn{6}{|l|}{ Vegetable (g) } \\
\hline Intervention & 69 & $41 \cdot 1$ & $52 \cdot 1$ & $48 \cdot 6$ & \multirow{2}{*}{$0 \cdot 823$} \\
\hline Control & 70 & $58 \cdot 1$ & $55 \cdot 4$ & $42 \cdot 3$ & \\
\hline \multicolumn{6}{|c|}{ Fruit and vegetable $(\mathrm{g})$} \\
\hline Intervention & 202 & $101 \cdot 9$ & 235 & $151 \cdot 2$ & \multirow{2}{*}{0.617} \\
\hline Control & 170 & $109 \cdot 6$ & 163 & $109 \cdot 6$ & \\
\hline
\end{tabular}

${ }^{*}$ For details of the project, see p. 542.

Health Organization/Food and Agriculture Organization, 2003), but intakes of fruit and vegetables are low and fall short of the recommended $400 \mathrm{~g} / \mathrm{d}$. The recent national survey of British adults (Henderson \& Gregory, 2002) has reported average daily fruit and vegetable intakes of $231 \mathrm{~g}$ for women and $218 \mathrm{~g}$ for men. Concern about low fruit and vegetable consumption has led to the widespread promotion of an increase in fruit and vegetables via the "five-aday' programmes (Havas et al. 1994; Department of Health, 2000) and other initiatives such as the School Fruit Scheme in England (Department of Health, 2004b). Intakes of fruit and vegetables among children are a particular concern, not least because dietary habits in childhood will affect not only growth and development in childhood but also disease risk throughout life. In addition, as discussed earlier, patterns of food intake track into adulthood. In a survey of children aged 4-18 years (Gregory et al. 2000) average fruit and vegetable intakes have been found to be low $(<200 \mathrm{~g})$. Schools present an opportunity to effect dietary change, particularly during early school years when children's food preferences and eating habits are being formed.

The Bash Street Kids Project was a school-based nutrition education intervention that aimed to increase fruit and vegetable intake in primary school-aged children. This intervention used several elements of intervention that evidence suggests are likely to be successful (Table 2). Based on the principle of learning theory, this intervention involved the whole school and included: increasing the provision of fruit and vegetables in schools through both school lunches and tuck shops; providing the opportunity for tasting of familiar and novel fruit and vegetables; communications within the school; developing and using learning materials in the curriculum; involving the family through newsletters. The characters from The Bash Street Kids, adapted to present a positive image of fruit and vegetables, were used throughout the materials (C) DC Thomson \& Co. Ltd).

The intervention took place in four primary schools in the city of Dundee, Scotland and was led by Professor A Anderson (for further details of this project, see Anderson et al. 2001; Higgins et al. 2001; AS Anderson, LEG
Porteous, E Foster, C Higgins, M Stead, M Hetherington, M-A Ma and AJ Adamson, unpublished results). Evaluation of the intervention included cognitive and attitudinal assessments as well as assessments of food and nutrient intake ( $3 \mathrm{~d}$ food diaries). Age-appropriate cognitive and attitudinal assessments examined beliefs, attitudes and knowledge relating to fruit and vegetables based on the theory of planned behaviour (Ajzen, 1985). Measurements were made at baseline and 9 months after the implementation of the programme.

A total of 138 children (47\% of the total sample) completed cognitive and attitudinal assessments and 128 (44\% of the possible sample) children completed food diaries. The tasting opportunities were found to be effective; children in the intervention group had tasted more fruit and vegetables compared with control group $(P<0 \cdot 001)$. Knowledge improved $(P=0.02)$ and children in intervention schools had increased awareness of the social pressure to consume fruits and vegetables (subjective norm). The mean daily intake of fruit was significantly greater in the children in intervention schools compared with controls $(P=0 \cdot 042$; Table 4). Vegetable intake showed no significant change in either group. It was concluded that a whole-school approach to increasing fruit and vegetable consumption had been successful in changing attitudes, knowledge and consumption of fruit (by approximately 0.5 portion daily) but not vegetables.

An increase of 0.5 portion of fruit daily is consistent with findings from other studies promoting fruit and vegetable consumption (Nicklas et al. 1998; Baranowski et al. 2000), and against the background of low intakes of fruit and vegetables of children this change is meaningful. Other authors have also reported a lack of impact on vegetable intakes and have concluded that targetted interventions that focus specifically on vegetables are necessary (Trudeau et al. 1998).

Interventions in a school setting offer opportunities to effect dietary change both directly by change in food provision within school and also by changing knowledge and attitudes. Preschools or nurseries also offer an opportunity for intervention. A recent study in the US 'Healthy Start' project (Williams et al. 2004) has evaluated the impact of 
a multi-component cardiovascular health intervention that included food service in a preschool population, with a primary outcome of change in serum cholesterol from the beginning to the end of the school year. The intervention was effective in reducing serum cholesterol in the study population as a whole and specifically in those children with initial elevated serum cholesterol levels. Other studies that have targetted the school environment and policy in relation to diet and activity in older children have been less successful in promoting positive change (Sallis et al. 2003). There is a need for a better understanding of the barriers to the implementation of health-promoting policy in schools. Current work in this area will help to elucidate these barriers (Department of Health 2004c).

\section{The Family Food and Health Project}

Energy-dense high-fat intakes are associated with increased risk of CVD, obesity and cancer. Recently, the energy density of foods has received new attention, with evidence suggesting that man has a weak innate ability to recognise foods with a high energy density, which leads to 'passive over consumption', and that energy density of foods is a key determinant of energy intake (Prentice \& Jebb, 2003). Population measures with an overall aim of reducing the energy density of diets may be one effective strategy in combating the obesity epidemic (Crowe et al. 2004). Despite consistent public health messages to reduce fat intake issued over more than a decade, these 'negative messages' appear to have had only a limited effect. An alternative strategy to advocating a reduction in fat intake may be a 'positive' message encouraging an increase in low-fat starchy foods with the aim of facilitating a reduction in fat intake. The acceptability or effectiveness of this 'positive' approach is not known, although some evidence suggests the efficacy of this approach warrants investigation (van Assema et al. 2001). A survey of UK consumers has revealed highly divergent attitudes and beliefs in relation to starchy foods. While starchy foods are viewed to be good for health they are also seen as being high in energy and not helpful in weight control. The overall intention to increase starchy food intake is extremely low. The barriers identified include the belief that the intake of starchy food is already high and that starchy foods should be reduced to achieve a healthier diet (Stubenitsky \& Mela, 2000).

The Family Food and Health Project undertaken in Newcastle upon Tyne between 1998 and 2000 incorporated a number of the key elements of effective intervention (Table 2). Further details of this study have been published (Adamson et al. 2000, 2001; Curtis et al. 2001a,b, 2002; Tohill et al. 2001; PJ Curtis, AJ Adamson and JC Mathers, unpublished results).

The aim of the Family Food and Health Project was to determine the acceptability and effectiveness, in terms of promoting a reduction in fat intake, of an increased intake of low-fat starchy foods. The rationale for using a familybased intervention was that most food is eaten within the home. Furthermore, family dynamics may have an important influence on the effectiveness of interventions, and families could provide a network of support for change
(Table 1; De Bourdeaudhuij \& Brug, 2000). The family's liking for starchy foods has been found to enhance the reported intention to increase starchy food consumption in individuals (Stubenitsky \& Mela, 2000).

Families (any number of adults with at least one child aged $<16$ years) were recruited to a randomised trial by census enumeration districts. Of 206 families recruited, 169 families reported (by $3 \mathrm{~d}$ estimated food diaries that were quantified at interview with a nutritionist) $>35 \%$ food energy (FE) from fat and $<29 \%$ FE from starch and were allocated by enumeration districts to one of three interventions. The aim of each intervention was to promote consumption of low-fat starchy foods. Intervention A (health fayre), based on communication theory, was a single interactive information-based session, which included food tasting, for all the family. Intervention B (cook and eat) was four small group sessions that were practical and food-based. Intervention $\mathrm{C}$ (personalised advice) included the components of interventions $\mathrm{A}$ and B but also goal setting and support for change. All interventions were delivered by experienced community dietitians. Dietary intake was assessed 3 months after the end of the intervention.

Mean starch intake for all families $(29.1 \% \mathrm{FE})$ was $2.7 \%$ FE units higher at 3 months post intervention than at baseline and was above the Family Food and Health Project target $(P<0 \cdot 05$; Fig. 2). All intervention groups were close to or above the target intake for starch, with the increases in starch achieved by the intervention groups in the order $\mathrm{C}>\mathrm{B}>\mathrm{A}$ (increases of $3.4,2.8$ and $2.2 \% \mathrm{FE}$ units respectively). Mean fat intake of $35.4 \%$ FE was

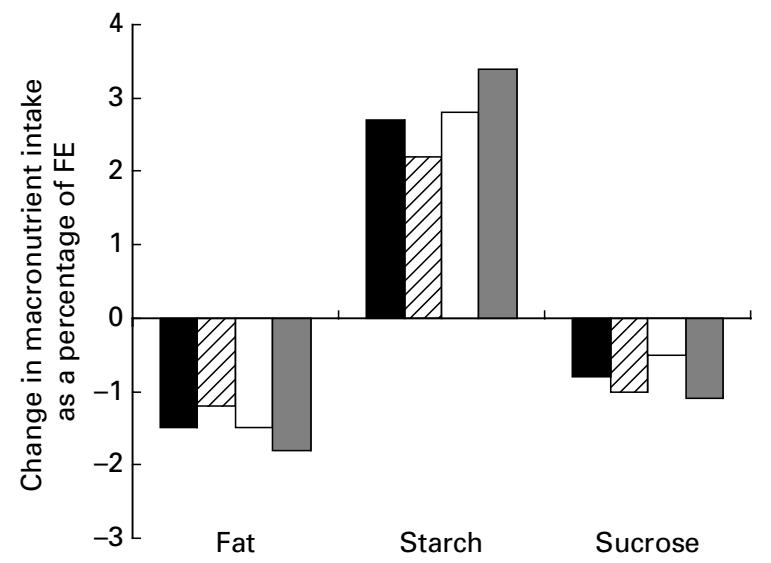

Fig. 2. The Family Food and Health Project: family changes in macronutrient intake from baseline to 3 months after the end of the intervention, grouped by intervention. The families were allocated to one of three interventions. The aim of each of the interventions was to promote consumption of low-fat starchy foods. Intervention A (health fayre; $\square$ ), based on communication theory, was a single interactive information-based session, which included food tasting, for all the family. Intervention B (cook and eat; $\square$ ) was four small group sessions that were practical and food based. Intervention C (personalised advice; $\square$ ) included the components of interventions $A$ and $B$ but also goal setting and support for change (Adamson et al. 2000; for further details of the study, see p. 544). (ם), All interventions. No. of families: total, 134, intervention A 51 , intervention B 43, intervention C 40. FE, food energy. 
$1.5 \% \mathrm{FE}$ units lower at 3 months post intervention than at baseline. Only intervention $\mathrm{C}$ met the dietary target for fat $(34 \cdot 2 \% \mathrm{FE})$ at 3 months post intervention; the reductions in fat were in the order $\mathrm{C}>\mathrm{B}>\mathrm{A}$ (decreases of $1.8,1.5$ and $1.2 \% \mathrm{FE}$ units respectively). Mean sucrose intake was reduced by $0.9 \% \mathrm{FE}$ units to $9.1 \% \mathrm{FE}$ with reductions ranging from $0.5 \%$ units (intervention $\mathrm{B}$ ) to $1.1 \%$ units (intervention $\mathrm{C}$ ). Whilst there were no statistically significant differences in the efficacy of the interventions in increasing starch intake and reducing fat intake at 3 months post intervention, there was a consistent stepwise trend in increasing effect (as \% FE) with the intensity of intervention $\mathrm{C}>\mathrm{B}>\mathrm{A}$. In terms of absolute intake intervention groups $\mathrm{B}$ and $\mathrm{C}$ were the only groups to increase starch and reduce fat (expressed in $\mathrm{g} / \mathrm{d}$ ) between baseline and 3 months post intervention (Fig. 2).

The aim of the Family Food and Health Project was to promote an increase in low-fat starchy food and to test the effectiveness of this positive message in promoting reductions in fat intake. When expressing the relationship between starch and fat as a percentage of the FE, an increase in starch of 1 unit was associated with a reduction in fat of 0.42 units. The Family Food and Health Project was successful in promoting an increase in starch consumption and this increase in starch was associated in turn with a reduction in intake of both fat and sugar. While there was no significant difference between interventions there was an evident trend to suggest that the most intensive intervention, which included personalised advice and goal setting based on dietary assessment and support for change, was the most successful in promoting change. Intervention B, which included food-related activities in small group settings, also demonstrated potential to promote dietary change. These findings are consistent with the evidence for effective interventions (Table 1). This study further elucidates some of the barriers to an increased consumption of starchy foods that will need to be addressed at a public health level if low-fat high-starch low-energydensity foods are to replace high-fat high-energy-density foods.

\section{Conclusions}

Whilst the need for dietary change and the nature and extent of those changes are now well established, there is limited evidence for effective interventions that will produce sustained change in dietary behaviour in the general public. Given the complexities of eating behaviour and the ways in which food-related behaviours are intimately associated with a sense of self and are influenced profoundly by family, community and socio-economic circumstances, it should not be surprising that interventions that fail to address the context of food choice and eating events are often ineffective. The 'success' factors summarised in Table 1 provide a basis for further research on which to base effective interventions. However, there are substantial gaps in the portfolio of research approaches for such work, not least the lack of robust procedures for assessing dietary change. The limitations of current reporting tools for quantifying habitual diet are well known. Also, these limitations are amplified when attempting to assess change, because the subjects are necessarily aware of what dietary behaviour is expected and because repeat measurements are burdensome. The use of biomarkers of dietary exposure is an attractive option, but existing biomarkers assess only certain aspects of the diet and are very poorly developed for assessing, for example, exposure to dietary carbohydrates. It has been suggested (Mathers, 2004) that the current explosion of research on epigenetic marking of the genome by environmental factors may offer novel opportunities for the development of new exposure markers. In addition, changes in biomarkers of disease risk, e.g. waist circumference, blood pressure or blood lipid concentrations, should be used in conjunction with assessments of dietary change where appropriate.

To be effective, change in the national diet must be supported by national leadership and through policies that address not only the individual but also the environment in which the individual lives, their access to high-quality information and health care, as well as to appropriate food choices and opportunities for other positive lifestyle choices such as decreasing inactivity. Egger et al. (2003) argue that the traditional epidemiological triad of host, vectors and environment may be a useful model for the management of the obesity epidemic, rather than specific isolated approaches, because the key players, including legislators, health professionals, government and industry, can see their roles in attenuating and eventually reversing the epidemic. This approach is likely to have application to all diet-related chronic disease.

\section{Acknowledgements}

We thank the funding bodies that have supported the work presented. The ASH30 Study was funded by the Wellcome Trust; the BiO Project was funded by Northern and Yorkshire NHS Executive; the Bash Street Kids Project and the Family Food and Health Project were both funded by the Food Standards Agency. Acknowledgement is also due to those who worked on the studies: Dr Angela Craigie and Dr Amelia Lake (ASH30 Study); Dr Helen Moore, Mr Darren Greenwood and all the $\mathrm{BiO}$ team for the $\mathrm{BiO}$ Project; Professor Annie Anderson, who was principal investigator for the Bash Street Kids Project; Mr Peter Curtis and colleagues on the Family Food and Health Project.

\section{References}

Adamson AJ, Curtis P, Loughridge J, Rugg-Gunn A, Spendiff A \& Mathers J (2000) A family-based intervention to increase consumption of starchy foods. Nutrition and Food Science 30, $19-23$.

Adamson AJ, Spendiff A, Curtis PJ, Jones A \& Mathers JC (2001) Relationship between consumer attitudes to starchy foods and starch consumption. Proceedings of the Nutrition Society 60, 184A.

Ajzen I (1985) From intentions to actions: a theory of planned behaviour. In Action-Control: From Cognition to Behaviour, pp. 11-39 [J Kuhl and J Beckman, editors]. Heidelberg, Germany: Springer.

Ammerman A, Lindquist C \& Hersey J (2001) Evidence Report on the Efficacy of Interventions to Modify Dietary Behaviour 
Related to Evidence Risk. Rockville, MD: Agency for Healthcare Research and Quality.

Ammerman AS, Lindquist CH, Lohr KN \& Hersey J (2002) The efficacy of behavioural interventions to modify dietary fat and fruit and vegetable intake: A review of the evidence. Preventive Medicine 35, 25-41.

Anderson AS, Adamson A, Hetherington MM, Foster E, Porteous L \& Higgins C (2001) Results from a school-based nutrition education intervention aimed at increasing fruit and vegetable intake in primary school aged children. Proceedings of the Nutrition Society 60, 143A.

Baranowski T, Davis M, Reniscow K, Baranowski J, Doyle C, Lin LS, Smith M \& Wang DT (2000) Gimme 5 fruit, juice, and vegetables for fun and health: outcome evaluation. Health Education and Behaviour 27, 96-111.

Craigie AM, Lake AA, Wood C, Gibbons M, Rugg-Gunn AJ, Mathers JC \& Adamson AJ (2003) Tracking of adiposity and dietary intake from adolescence to adulthood: a longitudinal study. International Journal of Obesity 27, Suppl. 1, S9.

Craigie AM, Lake AA, Wood C, Gibbons M, Webster S, Adamson AJ, Rugg-Gunn AJ \& Mathers JC (2002) The stability of nutrient intake between adolescence and adulthood: a 21-year follow-up. Proceedings of the Nutrition Society 61, $105 \mathrm{~A}$.

Crowe TC, Fontaine HL, Gibbons CJ, Cameron-Smith D \& Swinburn BA (2004) Energy density of foods and beverages in the Australian food supply: influence of macronutrients and comparison to dietary intake. European Journal of Clinical Nutrition; available as advanced online publication: doi:10.1038/sj.ejen.1601994

Curtis PJ, Adamson AJ \& Mathers JC (2001a) Associations between fruit and vegetable, starch and fat consumption? Proceedings of the Nutrition Society 60, 183A.

Curtis PJ, Adamson AJ \& Mathers JC (2001b) The relationship between starch and fat consumption. Proceedings of the Nutrition Society 60, 70A.

Curtis PJ, Webster S, Adamson AJ \& Mathers JC (2002) Parental change in starch and fat intake, after a 'starchy food' intervention. Proceedings of the Nutrition Society 61, 106A.

De Bourdeaudhuij I \& Brug J (2000) Tailoring dietary feedback to reduce fat intake: an intervention at the family level. Health Education Research 15, 449-462.

Department of Health (1991) Dietary Reference Values for Food Energy and Nutrients for the United Kingdom. Report on Health and Social Subjects no. 41. London: H. M. Stationery Office.

Department of Health (2000) The NHS Cancer Plan. London: The Stationery Office.

Department of Health (2002) Health improvement and prevention. National service frameworks: a practical aid to implementation in primary care. www.doh.gov.uk/pricare/pdfs/ nsf_healthimprovement.pdf

Department of Health (2004a) Choosing Health? Choosing a Better Diet: A Consultation on Priorities for a Food and Health Action Plan. London: The Stationery Office.

Department of Health (2004b) School fruit and vegetable scheme. www.dh.gov.uk/PolicyAndGuidance/HealthAndSocialCare Topics/FiveADay/FiveADayGeneralInformation/FiveADay GeneralInformation/fs/en?CONTENT_ID=4002149\&chk= DeYbs5

Department of Health (2004c) Food in Schools programme. http://www.dh.gov.uk/PolicyAndGuidance/HealthAndSocial CareTopics/FoodInSchools/fs/en

Department of Health, Chief Medical Officer (2003) Health Check: On the state of the public health. Annual report of Chief Medical Officer 2002. www.dh.gov.uk/Publications AndStatistics/Publications/AnnualReports/CMOAnnualReports Article/fs/en?CONTENT_ID=4006432\&chk=2qDtw4
Diabetes Prevention Program Research Group (2002) Reduction in the incidence of type II diabetes with lifestyle intervention or metformin. New England Journal of Medicine 346, 343-403.

Egger G, Swinburn B \& Rossner S (2003) Dusting off the epidemiological triad: could it work with obesity? Obesity Reviews 4, 115-119.

Ehtisham S, Hattersley AT, Dunger DB \& Barrett TG (2004) First UK survey of paediatric type 2 diabetes and MODY. Archives of Disease in Childhood 89, 526-529.

Gregory J, Lowe S, Bates CJ, Prentice A, Jackson LJ, Smithers G, Wenlock R \& Farron M (2000) National Diet and Nutrition Survey: Young People Aged 4-18 Years. vol. 1: Report of the Diet and Nutrition Survey. London: The Stationery Office.

Hackett AF, Rugg-Gunn AJ, Appleton DR, Eastoe JE \& Jenkins GN (1984) A 2-year longitudinal nutritional survey of 405 Northumberland children initially aged 11.5 years. British Journal of Nutrition 51, 67-75.

Harvey EL, Glenny AM, Kirk SF \& Summerbell CD (1999) A systematic review of interventions to improve health professionals' management of obesity. International Journal of Obesity and Related Metabolic Disorders 23, 1213-1222.

Havas S, Heimendinger J, Reynolds K, Baranowski T, Nicklas TA, Bishop D, Buller D, Sorensen G, Baresford SA, Cowan A \& Damron D (1994) 5 a day for better health: A new research initiative. Journal of the American Dietetic Association 94, 32-36.

Health Education Authority, Department of Health and Ministry of Agriculture Fisheries and Food (1994) The Balance of Good Health. London: H. M. Stationery Office.

Henderson L \& Gregory J (2002) The National Diet and Nutrition Survey: Adults Aged 19 to 64 Years. vol. 1: Types and Quantities of Foods Consumed. London: The Stationery Office.

Higgins C, Hetherington MM, Anderson AS, Porteous LEG, Foster E \& Adamson AJ (2001) Children's understanding of fruits and vegetables: implications for nutrition education. Proceedings of the Nutrition Society 60, 2A.

Hu FB, Manson JE, Stamfer MJ, Colditz G, Liu S, Solomon CG \& Willett WC (2001) Diet, lifestyle, and the risk of type II diabetes mellitus in women. New England Journal of Medicine 345, 790-797.

Key TJ, Allen NE, Spencer EA \& Travis RC (2002) The effect of diet on risk of cancer. Lancet 14, 861-868.

Lake AA, Rugg-Gunn AJ, Hyland RM, Craigie AC, Wood CE, Gibbons MR, Mathers JC \& Adamson AJ (2004) Longitudinal dietary change from adolescence to adulthood: perceptions, attributions and evidence. Appetite 42, 255-263.

Mathers JC (2004) Chairman's introduction: What can we expect to learn from genomics? Proceedings of the Nutrition Society 63, $1-4$.

Moore H, Greenwood D, Gill T, Waine C, Soutter J \& Adamson AJ (2003a) A cluster randomised trial to evaluate a nutrition training programme. British Journal of General Practitioners 53, 271-277.

Moore H, Summerbell CD, Greenwood DC, Tovey P, Griffiths J, Henderson M, Hesketh K, Woolgar S \& Adamson AJ (2003b) Improving management of obesity in primary care: cluster randomised trial. British Medical Journal 327, 1085.

Moore H, Summerbell CD, Vail A, Greenwood DC \& Adamson AJ (2001) The design features and practicalities of conducting a pragmatic cluster randomised trial of obesity management in primary care. Statistics in Medicine 20, 331-340.

National Audit Office (2001) Tackling Obesity in England: Report by the Comptroller and Auditor General. London: The Stationery Office; available at: www.nao.gov.uk/publications/ nao_reports/00-01/0001220es.pdf

Nicklas TA, Johnson CC, Myers L, Farris RP \& Cunningham A (1998) Outcomes of a high school program to increase fruit 
and vegetable consumption: Gimme 5 - a fresh nutrition concept for students. Journal of School Health 68, 248-253.

Pignone MP, Ammerman A, Fernandez L, Orleans CT, Pender N, Woolf S, Lohr K \& Sutton S (2003) Counselling to promote a healthy diet in adults: A summary of the evidence for the U.S. Preventive Services Task Force. American Journal of Preventive Medicine 24, 75-92.

Prentice AM \& Jebb SA (2003) Fast foods, energy density and obesity: a possible mechanistic link. Obesity Reviews 4, 187-194.

Roe L, Hunt P, Bradshaw H \& Rayner M (1997) Health Promotion Interventions to Promote Healthy Eating in the General Population: A Review. London: Health Education Authority.

Sallis JF, McKenzie TL, Conway TL, Elder JP, Prochaska JJ, Brown M, Zive MM, Marshall SJ \& Alcaraz JE (2003) Environmental interventions for eating and physical activity: a randomised controlled trial in middle schools. American Journal of Preventive Medicine 24, 209-217.

Stampfer MJ, Hu FB, Manson JE, Rimm EB \& Willett WC (2000) Primary prevention of coronary heart disease in women through diet and lifestyle. New England Journal of Medicine 343, 16-22.

Stubenitsky K \& Mela DJ (2000) UK consumer perceptions of starchy foods. British Journal of Nutrition 83, 277-285.

Tohill UR, Curtis PJ, Adamson AJ \& Mathers JC (2001) Individual's perception of diet with regard to health compared with recorded intake. Proceedings of the Nutrition Society 60, $181 \mathrm{~A}$
Trudeau E, Kristal AR, Li S \& Patterson RE (1998) Demographic and psychosocial predictors of fruit and vegetable intakes differ: implications for dietary interventions. Journal of the American Dietetic Association 98, 1412-1417.

Tuomilehto J, Jousilahti P, Rastenyte D, Moltchanov V, Tanskanen A, Pietinen P \& Nissinen A (2001) Urinary sodium excretion and cardiovascular mortality in Finland: a prospective study. Lancet 357, 848-851.

Van Assema P, Martens M, Ruiter RA \& Brug J (2001) Framing of nutrition education messages in persuading consumers of the advantages of a healthy diet. Journal of Human Nutrition and Dietetics 14, 435-442.

Wardle J (1995) Parental influences on children's diets. Proceedings of the Nutrition Society 54, 747-758.

Williams CL, Strobino BA, Bollella M \& Brotanek J (2004) Cardiovascular risk reduction in preschool children: the 'Healthy Start' project. Journal of the American College of Nutrition 23, 117-123.

World Health Organization (2002) The World Health Report 2002: Reducing Risks, Promoting Healthy Life. Geneva: WHO.

World Health Organization/Food and Agriculture Organization (2003) Report of WHO/FAO Expert Consultation. Diet, Nutrition and the Prevention of Chronic Diseases. WHO Technical Report Series no. 916. Geneva: WHO.

Wright CM, Parker L, Lamont D \& Craft AW (2001) Implications of childhood obesity for health; findings from the thousand families cohort study. British Medical Journal 323, 1280-1284. 
https://doi.org/10.1079/PNS2004395 Published online by Cambridge University Press 